\title{
Limb salvage and vascular augmentation by microsurgical free flap transfer for treatment of neuropathic diabetic foot ulcers
}

\author{
Ichiro Hashimoto, Yoshiro Abe, Atsushi Morimoto, Keisuke Kashiwagi, \\ Keiichi Goishi, and Hideki Nakanishi \\ Department of Plastic and Reconstructive Surgery, the University of Tokushima Graduate School, \\ Tokushima, Japan
}

\begin{abstract}
Background : Neuropathic diabetic foot ulcers are generally deep and infectious wounds extending to the bone or joint. We performed microsurgical free flap transfer for limb salvage and vascular augmentation of feet with diabetic neuropathy. Methods : Angiography was performed to identify any significant arterial disease. The free flaps were transplanted after resection of the damaged skin and infected bone. Flow-through or endto-side anastomosis to the dorsalis pedis artery was performed to preserve the arterial blood flow to the residual foot. Results : An anterolateral thigh flap and free flaps based on the subscapular artery system were transplanted in 1 and 10 patients, respectively. All flaps survived. Arterial flow on the distal side of the anastomosis was postoperatively confirmed in all patients. During a mean follow-up period of 52 months, the long-term complications observed were recurrent ulcers in 4 patients. The limb salvage rate was $100 \%$, and $82 \%$ of patients achieved functional ambulation. Conclusions : Microsurgical flap transplantation is a safe and useful technique for minimal amputation of a diabetic neuropathic foot. Postoperative protection of the feet is important in order to avoid recurrence of foot ulceration. The use of protective footwear custom-tailored for each patient is strongly recommended. J. Med. Invest. 61 : 325-332, August, 2014
\end{abstract}

Keywords : diabetic foot, foot ulcer, diabetic neuropathies, microsurgery, free tissue flaps

\section{INTRODUCTION}

Foot ulceration precedes $85 \%$ of lower limb amputations in patients with diabetes mellitus (1). Foot ulcers develop during the lifetime of at least $15 \%$ of patients with diabetes and are a major cause of hospitalization among such patients $(1,2)$. Multiple diabetes-associated factors, including peripheral artery

Received for publication February 5, 2014 ; accepted February $21,2014$.

Address correspondence and reprint requests to Ichiro Hashimoto, M.D., Ph.D., Department of Plastic and Reconstructive Surgery, the University of Tokushima Graduate School, Kuramoto-cho, Tokushima 770-8503, Japan and Fax : +81-88633-7297. disease (PAD), neuropathy, and deformity, contribute to the development and persistence of lower extremity ulcers in patients with diabetes (3). In a report of 185 patients with diabetes, $41 \%$ had PAD and $61 \%$ had neuropathy ; furthermore, $45 \%, 16 \%$, and $24 \%$ of the patients had neuropathic, ischemic, and neuroischemic ulcers, respectively (4). The most frequent causes of lower extremity ulcers are reported to be trauma, neuropathy, and deformity (5). From these reports, peripheral neuropathy is thought to be the factor most responsible for foot ulceration. The peripheral neuropathy results in loss of the protective sensation of pain and in autonomic dysfunction including sympathetic denervation, dry 
skin, and warm feet. If not properly treated, these ulcers can develop complications, such as severe infection, joint destruction, osteomyelitis, and gangrene ; in some cases, amputation of the affected toe or limb is required. Complete or partial loss of metatarsal bone affects the arch of the foot and balance during walking. In order to preserve the metatarsal bone for as long as possible, we have treated neuropathic diabetic foot ulcers with transplantation of free flaps to the defects after resection of the damaged skin and infected bone. Because the condition of the artery of the limb is important for anastomosis of the artery and vein, angiography was performed to identify any significant arterial disease in all cases. The aim of this study was to evaluate, retrospectively, the results of free flap transposition surgery for treatment of diabetic neuropathic foot ulcers.

\section{PATIENTS AND METHODS}

Eleven patients who underwent free flap transfer for the treatment of neuropathic diabetic foot ulcer at Tokushima University Hospital from June 2002 through October 2012 were selected. All patients had been diagnosed with diabetic neuropathy of the lower limb after evaluation using Semmes-Weinstein monofilaments and/or electrophysiological study by neurologists. Radiography was performed to examine the depth of the foot ulcer, the extent of the fistula, and the condition of the foot bones. Computed tomography angiography (CT angiography) of the lower extremity was performed to screen for $\mathrm{PAD}$. In patients in whom CT angiography indicated the possibility of obstruction or stenosis, catheter angiography was performed for further examination, especially to identify any impairment of the vessels to be used for anastomosis. Debridement surgery was performed to remove the infection around the foot ulcer, and then a free flap (or flaps) was transplanted to cover the defect of the foot. End-toside anastomosis (6) or flow-throw anastomosis $(7,8)$ was used for the arterial anastomosis in order to preserve the peripheral flow of the recipient artery. One or 2 recipient veins selected from the vena comitans and/or cutaneous vein were used for venous anastomosis.

The following data were collected from the medical records and analyzed : 1) basic patient data including the sex, age, results of blood analysis including the blood glucose and hemoglobin A1c (HbA1c)
(National Glycohemoglobin Standardization Program) levels upon the first visit to our hospital, and the blood circulation index comprising the ankle brachial index (ABI) and skin perfusion pressure (SPP) measured before the surgery ; 2) the presence of stenosis and/or obstruction indicated by angiography of the lower limb ; 3) previous history of percutaneous transluminal angioplasty (PTA) ; 4) bacterial culture results ; 5) number of and procedure(s) used for debridement surgery ; 6) surgical procedure used for free flap transplantation, including the type of flap(s) transplanted, recipient vessels, and method of arterial anastomosis ; 7) rates of initial success, limb salvage (defined as preservation of the heel), and functional ambulation ; 8) all severe short- and long-term complications that required additional surgery or failed to heal during the follow-up period, i.e., within 30 days after the transplantation surgery (short-term complications) or after 31 days (long-term complications).

\section{RESULTS}

The 11 patients comprised 10 men and 1 woman ranging in age from 42 to 81 years (mean : 59 years). Their blood glucose and HbA1c levels upon the first visit to our hospital ranged from 171 to $400 \mathrm{mg} / \mathrm{dl}$ (mean : $248.7 \mathrm{mg} / \mathrm{dl}$ ) and from 6.4 to $15.4 \%$ (mean : $10.0 \%$ ), respectively. The ABI values for the ulceraffected and contralateral limbs ranged from 0.7 to 1.23 (mean : 1.11) and from 1.00 to 1.34 (mean: 1.17), respectively (Table 1 ). The SPP values for the ulcer-affected and contralateral legs ranged from 49 to $125 \mathrm{mmHg}$ (mean : $75 \mathrm{mmHg}$ ) and from 56 to 96 mmHg (mean : $75 \mathrm{mmHg}$ ), respectively.

Angiography identified stenosis of the lower limb artery in 6 patients, but no obstruction was detected in any case (Table 1 ). The PTA procedure was performed in 1 patient (case 11) who had severe stenosis of the popliteal artery. Bacterial culture was positive in all patients (Table 2). Five types of gram-positive cocci were detected in 8 patients and 3 types of gram-negative bacilli in 6 patients. Debridement surgery was performed in all patients, and debridement was performed only once in each case. The debridement surgeries included toe amputation at the level of the metatarsophalangeal (MTP) joint or the metatarsal bone in 2 and 6 patients, respectively (Table 1 ).

Six types of free flap were elevated from the subscapular artery system in 10 patients; in the 
Table 1. Patient summary

\begin{tabular}{|c|c|c|c|c|c|c|c|c|c|c|c|}
\hline No. & Sex & $\begin{array}{c}\text { Age } \\
(\mathrm{y})\end{array}$ & $\begin{array}{c}\mathrm{ABI} \\
\text { (affected side) }\end{array}$ & S & 0 & PTA & $\begin{array}{l}\text { Debridement surgery } \\
\text { (No. of toes, Location) }\end{array}$ & Free flap(s) and graft & $\begin{array}{l}\text { Anastomosis } \\
\text { method }\end{array}$ & $\begin{array}{l}\text { Short-term } \\
\text { complications }\end{array}$ & $\begin{array}{l}\text { Long-term } \\
\text { complications }\end{array}$ \\
\hline 1 & M & 42 & No data & + & 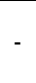 & - & $\begin{array}{l}\text { Necrotomy of calcaneal re- } \\
\text { gion }\end{array}$ & LDM flap and STSG & FT type & None & None \\
\hline 2 & M & 68 & No data & + & - & - & Necrotomy of dorsal region & SAF flap and STSG & FT type & None & None \\
\hline 3 & M & 70 & 1.18 & + & - & - & TA (1st toe, MTP joint) & Scapular flap & FT type & None & $\begin{array}{l}\text { None (AK amputation } \\
\text { on contralateral side) }\end{array}$ \\
\hline 4 & M & 59 & 1.21 & + & - & - & $\begin{array}{l}\text { TA (5th toe, metatarsal } \\
\text { bone) }\end{array}$ & $\begin{array}{l}\text { LDM flap, SAF flap, } \\
\text { and STSG }\end{array}$ & FT type & $\begin{array}{l}\text { Pressure ulcer } \\
\text { on calcaneus }\end{array}$ & None \\
\hline 5 & M & 81 & 1.08 & + & - & - & $\begin{array}{l}\text { Necrotomy of the Lisfranc } \\
\text { joint }\end{array}$ & LDM flap and STSG & FT type & None & $\begin{array}{c}\text { Recurrent ulcer } \\
\text { (Lisfranc amputation) }\end{array}$ \\
\hline 6 & M & 42 & 1.05 & - & - & - & TA (2nd toe, MTP joint) & TAP flap & FT type & None & $\begin{array}{c}\text { Recurrent ulcer } \\
\text { (conservative treatment) }\end{array}$ \\
\hline 7 & $\mathrm{~F}$ & 43 & 1.21 & - & - & - & $\begin{array}{l}\text { TA (2nd, 3rd, and 4th toes, } \\
\text { metatarsal bone) }\end{array}$ & ALT flap & FT type & None & None \\
\hline 8 & M & 70 & 1.16 & - & - & - & $\begin{array}{l}\text { TA (2nd toe, metatarsal } \\
\text { bone) }\end{array}$ & TAP flap & End-to-side & None & $\begin{array}{c}\text { Recurrent ulcer } \\
\text { (conservative treatment) }\end{array}$ \\
\hline 9 & M & 56 & 1.23 & - & - & - & $\begin{array}{l}\text { TA ( } 2 \text { nd, 3rd, } 4 \text { th, and } 5 \text { th } \\
\text { toes, metatarsal bone) }\end{array}$ & LDMC flap & End-to-side & None & None \\
\hline 10 & M & 55 & 1.17 & - & - & - & $\begin{array}{l}\text { TA (2nd, 3rd, and 4th toes, } \\
\text { metatarsal bone) }\end{array}$ & LDMC flap & FT type & $\begin{array}{l}\text { Wound } \\
\text { dehiscence }\end{array}$ & $\begin{array}{l}\text { Recurrent ulcer } \\
\text { (amputation of 5th toe) }\end{array}$ \\
\hline 11 & M & 63 & 0.7 & + & - & + & $\begin{array}{l}\text { TA (2nd, 3rd, and 4th toes, } \\
\text { metatarsal bone) }\end{array}$ & LDMC flap & FT type & None & None \\
\hline
\end{tabular}

ABI : Ankle brachial index, S : Stenosis, O : Obstruction, PTA : Percutaneous transluminal angioplasty, TA : Toe amputation, LDM : Latissimus dorsi muscle, STSG : Split-thickness skin graft, SAF : Serratus anterior fascia, MTP : metatarsophalangeal, TAP : Thoracodorsal artery perforator, ALT : Anterolateral thigh, LDMC : Latissimus dorsi musculocutaneous, FT : Flow-through, AK : Above knee

Table 2. Wound culture results

\begin{tabular}{ll}
\hline Bacteria cultured & Patient Number \\
\hline Methicillin-resistant Staphylococcus aureus & $1,3,5,6,10$ \\
Methicillin-sensitive Staphylococcus aureus & 2,4 \\
Pseudomonas aeruginosa & 3,8 \\
Escherichia coli & 7,11 \\
Enterococcus faecalis & 4,10 \\
Enterobacter cloacae & 4,6 \\
Enterococcus faecium & 9 \\
Streptococcus agalactiae & 6 \\
\hline
\end{tabular}

remaining patient, an anterolateral thigh flap was used because of the very thick fatty tissue around her back (Table 1). The dorsalis pedis artery was selected for arterial anastomosis in all patients. The flow-through type and end-to-side type of anastomosis were adopted in 9 and 2 patients, respectively. The flap vein was anastomosed with 1 dorsalis pedis vein in 5 patients, 1 great saphenous vein in 2 patients, and both the vena comitans and the great saphenous vein in 4 patients. The free flap transplantation succeeded in all patients (Figs. 1-5).

The short-term complications observed were a pressure ulcer in the calcaneal region and wound dehiscence ; the long-term complications observed were recurrent ulcers in 4 patients. This complication was treated conservatively or with amputation at the Lisfranc joint or 5 th toe (Table 1). One patient (patient 5) was unable to walk after Lisfranc joint amputation. Patient 3 underwent below-theknee amputation of the leg contralateral to the foot on which free flap transplantation had been performed (Fig. 3). The mean duration of follow-up was 52 months (range : $12-123$ months). The limb salvage rate was $100 \%$, and 9 of 11 patients (82\%) achieved functional ambulation.

\section{Case reports}

Case 3 : A 70-year-old man was referred to our hospital because of necrosis of the big toe and a deep ulcer affecting the first MTP joint of the right foot (Fig. 1A). After debridement of the necrotic tissue and confirmation that the wound was free of bacteria, a free scapular flap was transplanted with flow-through anastomosis to the dorsalis pedis artery (Fig. 1B and C). The patient's first metatarsal bone and walking function have been preserved for 10 years (Fig. 1D). Angiography of his leg before the free flap surgery showed arterial stenosis, including wall irregularity; however, no obstruction was detected (Fig. 2A and B). Angiography after the 

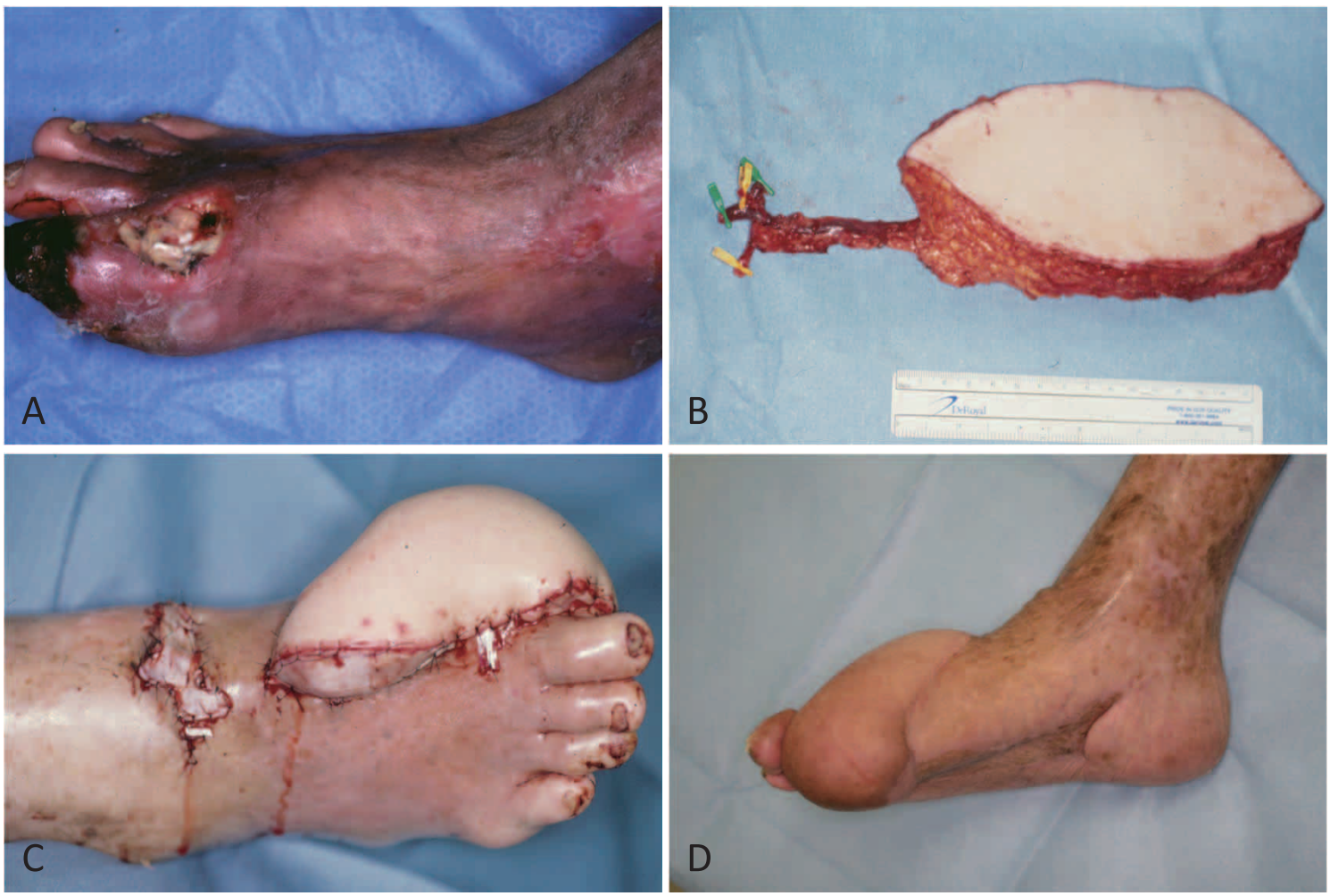

Fig. 1 : Case 3. Diabetic neuropathic foot ulcer of the right foot. A : A photograph taken during the first visit to the outpatient office.

B : A free scapular flap, on which the pedicle artery and veins are identified, is harvested from the patient's back. C : A photograph taken immediately after the free flap transplantation.

$\mathrm{D}$ : A photograph taken 10 years after the free flap transplantation.
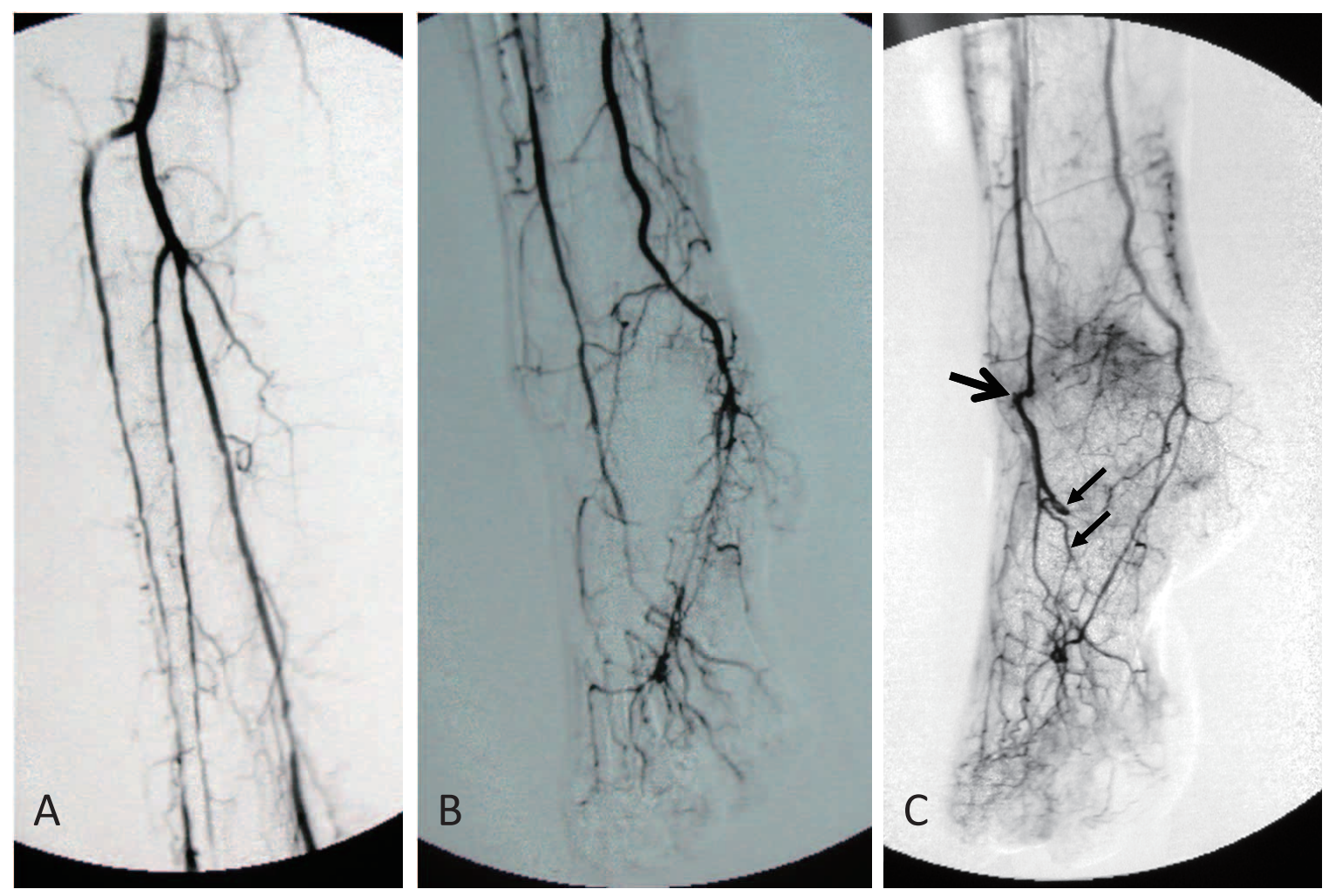

Fig. 2 : Case 3. Angiography of the right leg.

A, B : Angiography performed before the free flap surgery.

$\mathrm{C}$ : Angiography performed 5 years after the surgery. The large arrow shows the anastomosis between the flap artery and dorsalis pedis artery. The 2 small arrows show the nutrient artery in the flap. 
free flap transplantation showed intact blood flow from the dorsalis pedis artery and the posterior tibial artery to the foot and also that an additional artery, which was an arterial pedicle of the flap that had been anastomosed to the dorsalis pedis artery, was nourishing the foot through the transplanted free flap (Fig. 2C). Ten years after the free flap transplantation, his left foot was amputated because of an unhealed ulcer and limb ischemia that could not be treated with the PTA procedure or arterial bypass surgery (Fig. 3). The patient is walking using his right foot with the free flap and an artificial leg in place of the amputated left foot.

Case 11: A 63-year-old man was referred to our hospital because of an incurable ulcer and fistula affecting the second, third, and fourth MTP joints of the right foot (Fig. 4). Angiography of his leg showed $80 \%$ stenosis of the popliteal artery, which was treated with the PTA procedure before the free flap surgery. In the first surgery, the infected toes and the associated MTP joints and injured skin were resected (Fig. 4A, B). After confirmation that the wound was free of bacteria, a second surgery was performed in which a free latissimus dorsi musculocutaneous flap was transplanted to the defect (Fig. $4 \mathrm{C}, 5 \mathrm{~A})$. One year after the free flap transplantation, the patient can walk on his foot with assistance from custom-tailored shoes (Fig. 5B, C, D).

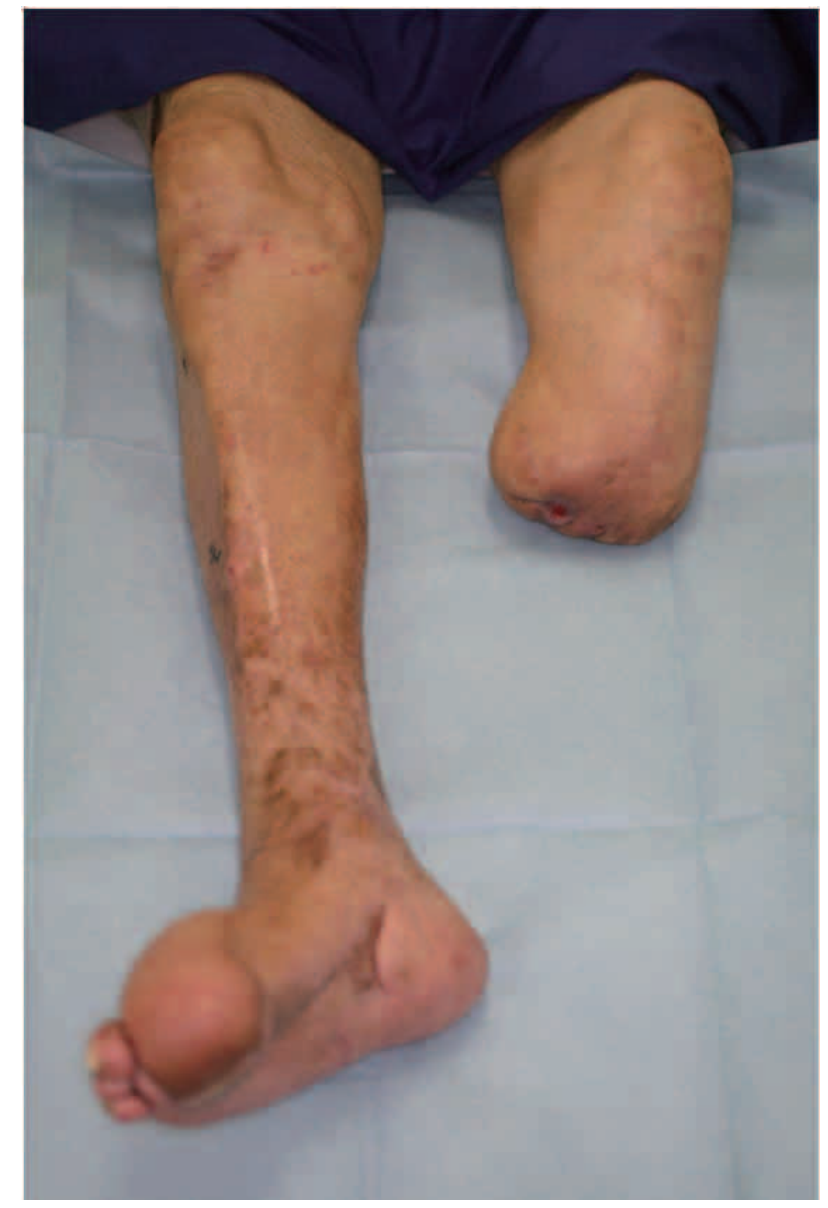

Fig. 3 : Case 3. A photograph of both legs taken 10 years after the free flap transplantation.
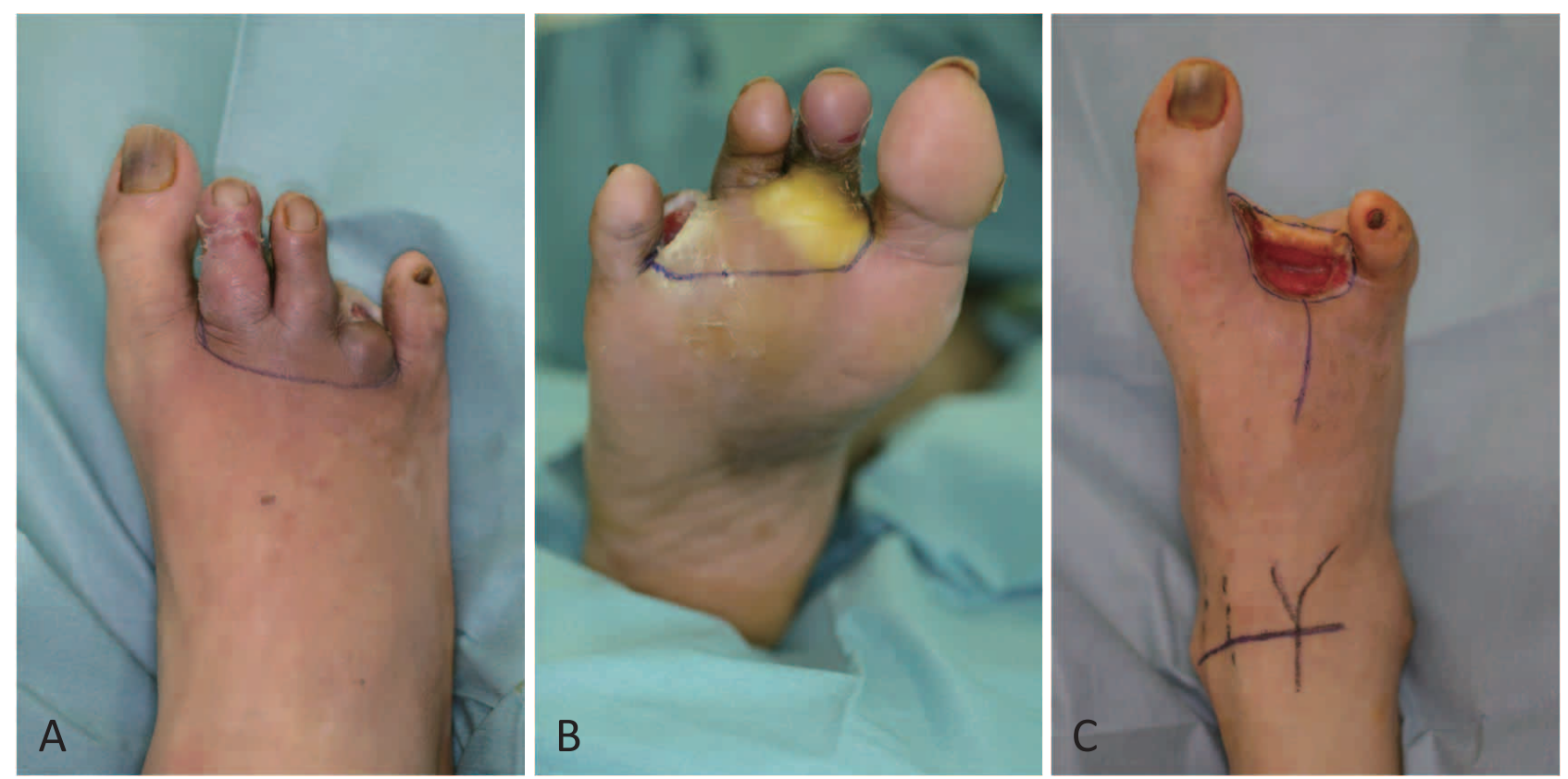

Fig. 4 : Case 11. Diabetic neuropathic ulcer of the right foot. A, B : Debridement surgery.

$\mathrm{C}$ : The second surgery for free flap transfer. 

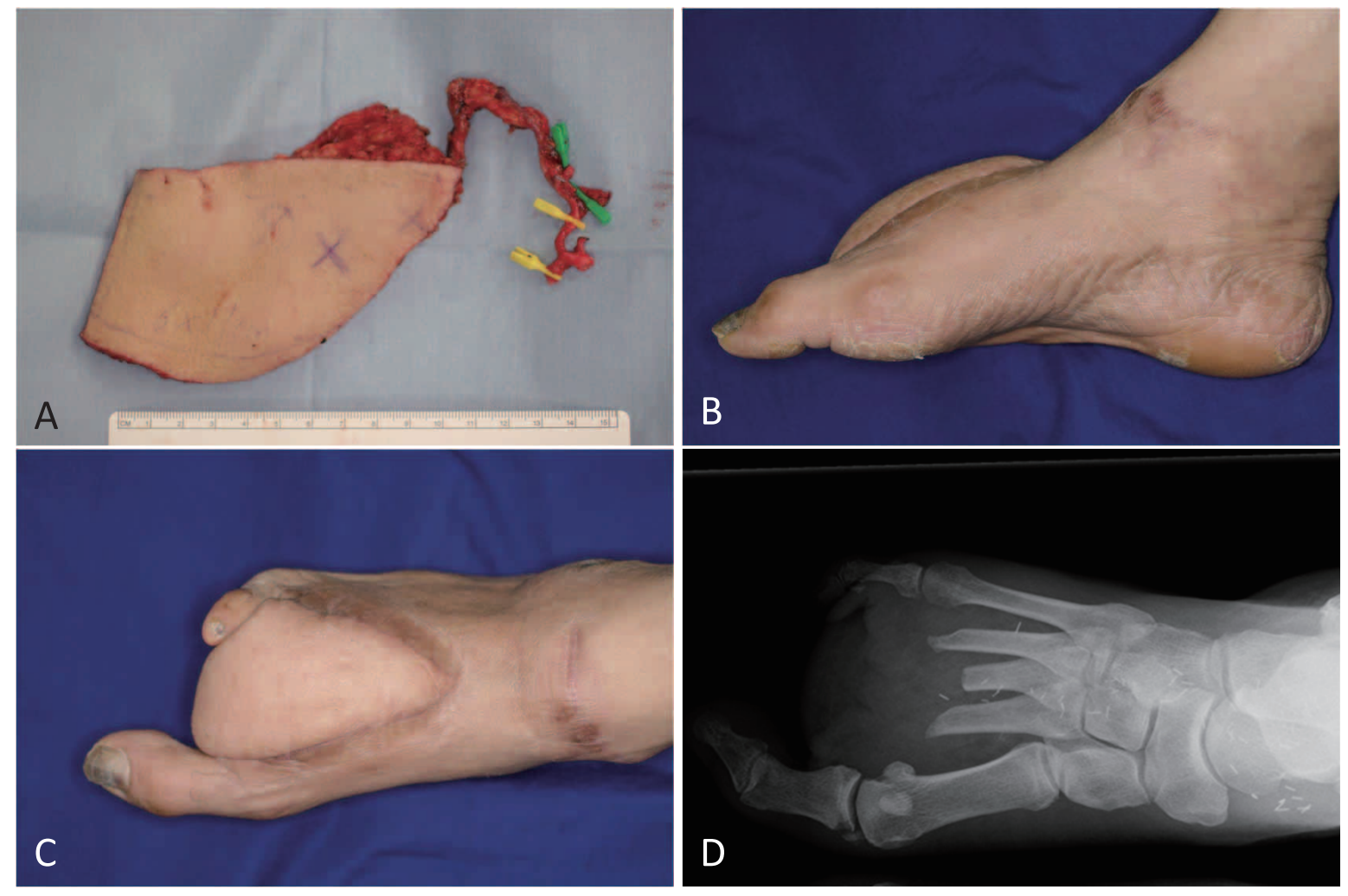

Fig. 5 : Case 11.

A: A free latissimus dorsi musculocutaneous flap, on which the pedicle artery and veins are identified, is harvested from the patient's back.

B, C : Photographs taken 1 year after the transplantation surgery. The arch of the foot is maintained.

$\mathrm{D}$ : Radiograph taken after the transplantation surgery. The metatarsal bones of all 5 toes is preserved.

\section{DISCUSSION}

The present study shows that free flap transplantation can be safely performed for treatment of a diabetic neuropathic foot ulcer. In a review of 528 patients, the success rate of free flap transfer to a diabetic foot ulcer was reported to be $92 \%$ (9). Others have reported that diabetes is not a contraindication to free flap reconstruction for limb salvage in selected patients $(10,11)$. One reason for the high success rate of the free flap transplantation in our series is that none of our patients had arterial obstruction and all had ABI values of $>1.0$ except for 1 patient who was therefore treated with a PTA procedure. Another possible reason is that the infectious lesions were completely debrided in all patients. Angiography detected arterial stenosis, including arterial wall irregularity, in 6 patients, and wall thickening of the recipient artery was observed under the surgical microscope during the process of anastomosing the blood vessels. Furthermore, although the veins of patients with diabetes are usually not damaged, we have encountered injury to the veins in the vicinity of severe infectious lesions. We believe that careful selection of the recipient veins to be anastomosed with the free flaps is vital to the success of the transplantation.

All of the patients in the present study had infected lesions containing bacteria. The fistula of a diabetic neuropathic foot ulcer is usually bone-deep because the skin, subcutaneous tissue, and even tendons are easily injured due to the diabetic sensory nerve dysfunction (12). The margins of the infected soft tissue and of osteomyelitis are unclear and difficult to detect in the operating room or with magnetic resonance imaging (13). Because we had time to observe the wound after debridement and thus confirm the eradication of the infection before the free flap transfer, aggressive or excessive debridement was unnecessary. In the 8 patients in whom toe amputation was performed, no non-affected tissue (including skin, subcutaneous tissue, and bone) had to be resected, and the resulting wound was covered with the free flap to allow preservation of longer portions of the metatarsal bone and sole skin. 
In the present study, end-to-side anastomosis or flow-through anastomosis was performed to preserve the blood flow of the dorsalis pedis artery. Diabetes affects the mortality rates of patients with PAD and critical limb ischemia (CLI) $(1,2)$. Although none of the patients in our study had developed CLI at the time of the transplantation of the free flap, we believe that preservation of the dorsalis pedis artery and the additional artery in the free flap is important for maintaining the blood flow to the foot to prevent a CLI crisis. Transplantation of free flaps to severely ischemic limbs using a bypass venous graft from the popliteal artery has been reported as a nutrient flap concept (14). The effect of the free flap on the ischemic limb can be explained by 1 ) the addition of a supplementary blood supply and an effective venous return system and 2) the progressive development of a new distal capillary bed (14). We also believe that the capillary or vascular bed provided by the free flap reduces the peripheral vascular resistance and thus helps to maintain the blood flow to the foot. We have recently experienced a case in which a patient required amputation of the leg contralateral to the foot that had undergone free flap transfer. Future studies may explore the effect of the additional blood supply provided by free flap transplantation on the feet of patients with diabetes.

A decubitus ulcer in the calcaneal region developed as a short-term complication in 1 patient ; the cause was diabetic sensory nerve dysfunction. Recurrence of foot ulceration was observed as a longterm complication in 4 patients and was also caused by anesthesia of the feet. It is important to protect the feet postoperatively in order to avoid such pressure sores and recurrence of foot ulcers. In everyday life, we have strongly recommended the use of protective footwear custom-tailored for each patient.

\section{DISCLOSURES}

Drs. Hashimoto, Abe, Morimoto, Kashiwagi, Goishi, and Nakanishi have no conflicts of interest or financial ties to disclose.

\section{REFERENCES}

1. Palumbo PJ, Melton LJ III : Peripheral vascular disease and diabetes. In : Harris MI, Hamman $\mathrm{RF}$, eds. Diabetes in America : diabetes data compiled 1984. U.S. Government Printing Office, Washington, DC, 1985, pp. 1-21

2. Mayfield JA, Reiber GE, Sanders LJ, Janisse D, Pogach LM : Preventive foot care in people with diabetes. Diabetes Care 21 : 2161-2177, 1998

3. Wieman TJ, Griffiths GD, Polk HC Jr, Ashmore JD, Ryan B, Das SK, Classen J, Johnson C : Management of diabetic midfoot ulcers. Ann Surg 215 : 627-632, 1992

4. Moulik PK, Mtonga R, Gill GV : Amputation and mortality in new-onset diabetic foot ulcers stratified by etiology. Diabetes Care 26 : 491494, 2003

5. Reiber GE, Vileikyte L, Boyko EJ, del Aguila M, Smith DG, Lavery LA, Boulton AJ : Causal pathways for incident lower-extremity ulcers in patients with diabetes from two settings. Diabetes Care 22 : 157-162, 1999

6. Frodel JL, Trachy R, Cummings CW : End-toend and end-to-side microvascular anastomoses : a comparative study. Microsurgery $7: 117-123$, 1986

7. Costa H, Guimarães I, Cardoso A, Malta A, Amarante J, Guimarães F : One-staged coverage and revascularisation of traumatised limbs by a flow-through radial mid-forearm free flap. Br J Plast Surg 44 : 533-537, 1991

8. Koshima I, Fujitsu M, Ushio S, Sugiyama N, Yamashita S : Flow-through anterior thigh flaps with a short pedicle for reconstruction of lower leg and foot defects. Plast Reconstr Surg 115 : 155-162, 2005

9. Fitzgerald O'Connor EJ, Vesely M, Holt PJ, Jones KG, Thompson MM, Hinchliffe RJ : A systematic review of free tissue transfer in the management of non-traumatic lower extremity wounds in patients with diabetes. Eur J Vasc Endovasc Surg 41 : 391-399, 2011

10. Hong JP : Reconstruction of the diabetic foot using the anterolateral thigh perforator flap. Plast Reconstr Surg 117 : 1599-1608, 2006

11. Ducic I, Attinger CE : Foot and ankle reconstruction : pedicled muscle flaps versus free flaps and the role of diabetes. Plast Reconstr Surg 128 : 173-180, 2011

12. Lipsky BA, Berendt AR, Cornia PB, Pile JC, Peters EJ, Armstrong DG, Deery HG, Embil JM, Joseph WS, Karchmer AW, Pinzur MS, Senneville E : 2012 Infectious Diseases Society of America clinical practice guideline for the diagnosis and treatment of diabetic foot infections. Clin Infect Dis 54 : 1679-1684, 2012 
13. Thorning C, Gedroyc WM, Tyler PA, Dick EA, Hui E, Valabhii J : Midfoot and hindfoot bone marrow edema identified by magnetic resonance imaging in feet of subjects with diabetes and neuropathic ulceration is common but of unknown clinical significance. Diabetes Care
$33: 1602-1603,2010$

14. Mimoun $\mathrm{M}$, Hilligot $\mathrm{P}$, Baux $\mathrm{S}$ : The nutrient flap : a new concept of the role of the flap and application to the salvage of arteriosclerotic lower limbs. Plast Reconstr Surg 84 : 458-467, 1989 